\title{
$\kappa$ Opioid Receptors in the Nucleus Accumbens Shell Mediate Escalation of Methamphetamine Intake
}

\author{
Timothy W. Whitfield, Jr., ${ }^{1}$ Joel E. Schlosburg, ${ }^{1}$ Sunmee Wee, ${ }^{2}$ Adam Gould, ${ }^{1}$ Oolivier George, ${ }^{1}$ Yanabel Grant, ${ }^{1}$ \\ Eva R. Zamora-Martinez, ${ }^{1}$ Scott Edwards, ${ }^{3}$ Elena Crawford, ${ }^{1}$ Leandro F. Vendruscolo, ${ }^{1}$ and George F. Koob ${ }^{1}$ \\ ${ }^{1}$ The Committee on the Neurobiology of Addictive Disorders, The Scripps Research Institute, La Jolla, California 92037, ${ }^{2}$ Department of Molecular \\ Therapeutics, Scripps Research Institute, Jupiter, Florida 33458, ${ }^{3}$ Department of Physiology, Alcohol and Drug Abuse Center of Excellence, Louisiana State \\ University Health Science Center, New Orleans, Louisiana 70112
}

Given that the $\kappa$ opioid receptor (KOR) system has been implicated in psychostimulant abuse, we evaluated whether the selective KOR antagonist norbinaltorphimine dihydrochloride (nor-BNI) would attenuate the escalation of methamphetamine (METH) intake in an extended-access self-administration model. Systemic nor-BNI decreased the escalation of intake of long-access (LgA) but not shortaccess (ShA) self-administration. nor-BNI also decreased elevated progressive-ratio (PR) breakpoints in rats in the LgA condition and continued to decrease intake after $17 \mathrm{~d}$ of abstinence, demonstrating that the effects of a nor-BNI injection are long lasting. Rats with an ShA history showed an increase in prodynorphin immunoreactivity in both the nucleus accumbens (NAc) core and shell, but LgA animals showed a selective increase in the NAc shell. Other cohorts of rats received nor-BNI directly into the NAc shell or core and entered into ShA or LgA. nor-BNI infusion in the NAc shell, but not NAc core, attenuated escalation of intake and PR responding for METH in LgA rats. These data indicate that the development and/or expression of compulsive-like responding for METH under LgA conditions depends on activation of the KOR system in the NAc shell and suggest that the dynorphin-KOR system is a central component of the neuroplasticity associated with negative reinforcement systems that drive the dark side of addiction.

Key words: dynorphin; escalation; kappa opioid receptors; methamphetamine; nucleus accumbens; substances of abuse

\section{Introduction}

Methamphetamine (METH) abuse is characterized by a range of compulsive behaviors, including a preoccupation with and repetitive seeking of the drug and a loss of control over intake. These compulsive aspects of METH abuse are highly treatment resistant and represent a major barrier to the treatment of human METH abusers. Based on the concept that addiction is characterized by a compulsion to take drugs and a loss of control over intake (American Psychiatric Association, 2000), an animal model of

\footnotetext{
Received May 10, 2013; revised Dec. 2, 2014; accepted Dec. 17, 2014.

Author contributions: T.W.W., S.W., L.F.V., and G.F.K. designed research; T.W.W., S.W., A.G., Y.G., E.R.Z.-M., and E.C. performed research; 0.G. contributed unpublished reagents/analytic tools; T.W.W., J.E.S., S.W., Y.G., E.C., S.E., L.F.V., and G.F.K. analyzed data; T.W.W., S.W., S.E., L.F.V., and G.F.K. wrote the paper.

This work was supported by National Institutes of Health Grant R01 DA010072 from the National Institute on Drug Abuse. Support was also provided by the Pearson Center for Alcoholism and Addiction Research at The Scripps Research Institute. Training for T.W.W. was provided by National Institute on Alcohol Abuse and Alcoholism Grant T32 AA007456 and National Institute on Drug Abuse Grant F32DA033726. This is publication number 24034 from The Scripps Research Institute. We thank Lauren Macshane and Jessie Margolis for their technical assistance in the self-administration models. We thank Michael Arends for assistance in manuscript preparation and editing and Drs. Jacqueline McGinty and Remi Martin-Fardon for helpful comments. Kevin Gormley at the National Institute on Drug Abuse generously provided nor-BNI.

The authors have no financial conflicts to disclose.

Correspondence should be addressed to Timothy W. Whitfield, Jr., Committee on the Neurobiology of Addictive Disorders, The Scripps Research Institute, 10550 North Torrey Pines Road, SP30-2400, La Jolla, CA 92037. E-mail: whitfiet@scripps.edu.

L.F. Vendruscolo's present address: Intramural Research Program, National Institutes of Health/National Institute on Drug Abuse, Baltimore, MD 21224.

G.F. Koob's present address: National Institute on Alcohol Abuse and Alcoholism, Rockville, MD 20852.

DOI:10.1523/JNEUROSCI.1978-13.2015

Copyright $\odot 2015$ the authors $\quad 0270-6474 / 15 / 354296-10 \$ 15.00 / 0$
}

extended-access METH self-administration that results in a progressive increase in drug intake (escalation) has been developed. Compulsive-like responding in these rodent models is hypothesized to be reflected in the escalation of drug intake, elevated breakpoints on a progressive-ratio $(\mathrm{PR})$ schedule of reinforcement, and increased levels of drug seeking (Ahmed and Koob, 1998; Kitamura et al., 2006; Wee et al., 2007; Mandyam et al., 2008; Rogers et al., 2008; Schwendt et al., 2009; Orio et al., 2010; Rocha and Kalivas, 2010; Hadamitzky et al., 2011; Parsegian et al., 2011; Reichel et al., 2011).

Dynorphins are opioid peptides derived from the prodynorphin precursor that are endogenous ligands for $\kappa$ opioid receptors (KORs; Chavkin et al., 1982; Watson et al., 1982). Prodynorphin expression is regulated by dopamine $\mathrm{D}_{1}$ receptor activation of cyclic adenosine monophosphate (cAMP) response element-binding protein (CREB) phosphorylation in the terminal regions of the mesocorticolimbic and nigrostriatal dopamine systems (Cole et al., 1995; Hyman et al., 1995; Simpson and McGinty, 1995; Carlezon et al., 1998). Dynorphins produce dysphoric-like effects and are thought to mediate negative emotional states associated with withdrawal from drugs of abuse (Mucha and Herz, 1985; Pfeiffer et al., 1986; Shippenberg et al., 2007; Wee and Koob, 2010). KORs are located on striatal dopaminergic and glutamatergic terminals (Svingos et al., 1999; Meshul and McGinty, 2000). Dynorphin-KOR interactions lead to receptor phosphorylation and extracellular signal-regulated kinase and p38 signaling (Bruchas et al., 2006; Bruchas and 
Chavkin, 2010). KOR blockade decreases basal and stimulantinduced extracellular levels of dopamine and glutamate in the nucleus accumbens (NAc; Gray et al., 1999).

Our central hypothesis is that KOR signaling during METH withdrawal leads to negative emotional states that drive compulsive-like METH craving and seeking when rats are allowed extended access to the drug. This hypothesis was tested using the selective, long-acting KOR antagonist norbinaltorphimine dihydrochloride (nor-BNI). Previous studies have shown that singular high doses of nor-BNI can produce long-lasting antagonism of KOR opioid signaling (Horan et al., 1992; Jones and Holtzman, 1992; Knoll et al., 2007; Wee and Koob, 2010; Chartoff et al., 2012) that can last from 1 to 3 months (Potter et al., 2011). nor-BNI was administered systemically and intra-NAc shell and core to test the hypothesis that dynorphins have a key role in the development (i.e., nor-BNI was given before extended-access sessions began) and/or expression (i.e., nor-BNI was still active during daily extended-access sessions) of escalation of METH intake and elevated PR breakpoints in extendedaccess animals. We showed that extended access to METH causes upregulation of prodynorphin in the NAc shell and that activation of dynorphin-KOR interactions in the shell but not core of the NAc plays a critical role in the development and/or expression of escalation of METH intake and elevated PR breakpoints.

\section{Materials and Methods}

Animals. All animal use procedures were approved by the The Scripps Research Institute Animal Care and Use Committee and were in accordance with National Institutes of Health guidelines (publication 85-23, revised 1996). Sixty-eight male Wistar rats (Charles River Laboratories), weighing 250-300 g at the start of the experiment, were housed three per cage in a temperature-controlled vivarium under a reverse light/dark cycle (lights off 8:00 A.M. to 8:00 P.M.). All of the experimental procedures were performed during the dark phase of the cycle. Three rats died during surgery, two rats did not acquire METH self-administration, two rats were excluded because of catheter failure, and one rat was excluded because of incorrect injector placement. Fifty-nine animals completed the study.

Surgical procedure. All of the rats were implanted with chronic indwelling intravenous catheters $(0.3 \mathrm{~mm}$ inner diameter $\times 0.64 \mathrm{~mm}$ outer diameter; Dow Corning) into the right external jugular vein as described previously (Wee et al., 2007). In anesthetized rats (1-3\% isoflurane in oxygen mixture), the catheter was passed subcutaneously from the back of the animal to the right external jugular vein. Catheters were flushed daily with $\sim 0.2 \mathrm{ml}$ of sterile saline solution that contained heparin ( 30 USP U/ml) and Timentin (ticarcillin disodium and clavulanate potassium in $3.0 \mathrm{~g} / 100 \mathrm{mg}$ proportion, $100 \mathrm{mg} / \mathrm{ml}$; GlaxoSmithKline).

METH self-administration. The rats were subsequently trained to selfadminister $0.05 \mathrm{mg} / \mathrm{kg}$ per infusion of METH during daily $1 \mathrm{~h}$ sessions under a fixed-ratio (FR) 1 schedule of reinforcement, in which one lever press resulted in a drug delivery. The National Institute on Drug Abuse provided methamphetamine hydrochloride. METH self-administration sessions were conducted in an operant chamber placed in a light- and sound-attenuating cubicle $(28 \times 26 \times 20 \mathrm{~cm}$; Med Associates $)$. The chamber had two retractable response levers mounted on a sidewall, and a stimulus light was mounted above each lever. At the start of a session, two response levers were presented in the chamber, and one response on the right lever resulted in the delivery of $0.1 \mathrm{ml}$ of a drug solution over $4 \mathrm{~s}$. The stimulus light above the active lever was illuminated at the onset of each infusion and remained illuminated throughout the infusion and 20 $s$ timeout period, during which responses were recorded but had no programmed consequences. The offset of the cue light signaled the availability of the next infusion. This has been our standard intravenous self-administration procedure (Roberts et al., 1980). Pressing the left (inactive) lever was recorded but had no programmed consequences. The session ended by the withdrawal of the levers from the chamber.
In Experiment 1, the rats were trained to self-administer METH on this FR1 schedule of reinforcement for $10 \mathrm{~d}$. The National Institute on Drug Abuse generously provided nor-BNI. When stable responding was achieved, the rats received a single systemic injection of nor-BNI (30 $\mathrm{mg} / \mathrm{kg}$ dissolved in sterile $\mathrm{H}_{2} 0$ ), which has been shown to have longlasting effects on psychostimulant-mediated behaviors (Potter et al., 2011; Chartoff et al., 2012) or vehicle (sterile $\mathrm{H}_{2} 0$ ) and were split into two groups: (1) long access (LgA; $6 \mathrm{~h}$ sessions, which produces escalation of drug intake) and (2) short access (ShA; 1 h sessions, which produces stable levels of drug intake). The rats then entered the escalation phase of the experiment, which consisted of 10 consecutive days of METH selfadministration under ShA or LgA conditions. All of the rats were then tested under a PR schedule of reinforcement. In this test, the workload to receive a drug infusion increases progressively, which can be used to evaluate the motivation for METH. For the PR schedule, the response requirement began at one response per injection and increased according to the following equation: responses/injection $=[5 \times e($ injection number $\times 0.2)]-5$ (Richardson and Roberts, 1996). When a rat failed to achieve the response requirement within $1 \mathrm{~h}$, the session ended. The rats were then subjected to 2 weeks of abstinence. After abstinence, all of the rats were tested again under a PR schedule of reinforcement and euthanized $24 \mathrm{~h}$ later.

Immunohistochemistry. In Experiment 2, a separate cohort of rats was trained as described above. When stable responding was achieved, the rats were split into ShA and LgA groups and entered the escalation phase of the experiment, along with a drug-naive group of littermate controls that were handled regularly but did not receive catheterization surgery and were not exposed to the operant chambers. Thus, we cannot completely rule out the possibility that surgery and other potentially stressful procedural variables may have contributed to the alterations in dynorphin levels. After 10 consecutive days of METH self-administration, the rats were anesthetized $24 \mathrm{~h}$ after the final escalation session with chloral hydrate $(35 \%, 3 \mathrm{ml} / 450 \mathrm{~g}$ body weight, i.p.) and transcardially perfused with cold $0.1 \mathrm{M}$ PBS and then $4 \%$ paraformaldehyde in $0.1 \mathrm{M}$ PBS, pH 7.4, for $20 \mathrm{~min}$ at a rate of $15 \mathrm{ml} / \mathrm{min}$. The brains were cryoprotected in $30 \%$ sucrose and coronally sectioned on a cryostat (Leica) at $40 \mu \mathrm{m}$, and the sections were stored in $0.1 \% \mathrm{NaN}_{3}$ in $0.1 \mathrm{M} \mathrm{PBS}$ at $4^{\circ} \mathrm{C}$ before being processed for immunohistochemistry.

Prodynorphin immunostaining was measured in the NAc core and shell with a rabbit polyclonal anti-prodynorphin antibody (1:1000; catalog \#ab11137; Abcam). All incubations were performed at room temperature unless indicated otherwise. Free-floating sections were rinsed in $0.1 \mathrm{M}$ PBS and incubated with $0.3 \% \mathrm{H}_{2} \mathrm{O}_{2}$ for $30 \mathrm{~min}$ to remove any endogenous peroxidase activity. Nonspecific binding was blocked with $5 \%$ donkey serum and $0.5 \%$ Tween 20 in $0.1 \mathrm{~m}$ PBS for $60 \mathrm{~min}$ and incubated with the primary antibody (in 5\% donkey serum and $0.5 \%$ Tween 20) for $48 \mathrm{~h}$ at room temperature. After washing with $0.1 \mathrm{M}$ PBS, the sections were incubated with ImmPRESS Anti-Rabbit immunoglobulin (peroxidase) polymer detection reagent for $1 \mathrm{~h}$ (Vector Laboratories). After incubation with the secondary antibody, the sections were stained using the VECTASTAIN ABC reagent (Vector Laboratories) for 8 min until specific staining in the ventral striatum was visible. Omission or dilution of the primary antibody resulted in a lack of specific staining, thus serving as a negative control for antibody experiments.

The analysis was performed with the experimenter blinded to the group analyzed to localize and quantify immunoreactivity. DAB staining of the coded slides was visualized and quantified with a Zeiss Axiophot photomicroscope. Staining was examined and determined to be present in both neurons and presynaptic terminals in the ventral striatum; therefore, integrated immunoreactivity density measures were obtained in six serial sections per animal. Specific staining in the NAc core and shell (anteroposterior, +2.28 to $+1.28 \mathrm{~mm}$; Paxinos and Watson, 2005) from both the left and right hemispheres was quantified, normalized to background staining in the same slide, and expressed as normalized integrated density (integrated gray density divided by the selected area) in each rat and averaged across rats within a group using NIH ImageJ software. A difference in the normalized integrated density across groups was found using one-way ANOVA, followed by Student-Newman-Keul's post hoc test (Prism 4.0; GraphPad Software). 
Intracranial infusions. In Experiment 3, separate cohorts of rats were trained to selfadminister METH for $10 \mathrm{~d}$ under baseline conditions as described above and were subsequently given a single, bilateral intracranial infusion of nor-BNI the day after the final baseline training session (i.e., before the start of self-administration sessions). A custom 33 gauge hypodermic injector, connected via Tygon tubing to a $10 \mu \mathrm{l}$ syringe (Hamilton) and protected with a 26 gauge guide, was inserted bilaterally into the NAc. After infusions, the injector was removed, the skull was sealed with bone wax (Ethicon), and the incision was sutured. The rats were treated with bilateral intracranial injections of nor-BNI $[4 \mu \mathrm{g} / 0.5 \mu \mathrm{l}$ per side in artificial CSF (aCSF)] or vehicle (aCSF) into the NAc shell (anteroposterior, $+1.7 \mathrm{~mm}$; mediolateral, $\pm 0.8 \mathrm{~mm}$; dorsoventral, $-7.0 \mathrm{~mm}$ from dura; Paxinos and Watson, 2005) or core (anteroposterior, $+1.7 \mathrm{~mm}$; mediolateral, $\pm 1.3 \mathrm{~mm}$; dorsoventral, $-7.0 \mathrm{~mm}$ from dura; Paxinos and Watson, 2005) and split into LgA and ShA groups. Rats selfadministered METH as described in Experiment 1 for the duration of the experiment. After the final PR test, the rats were euthanized, and the brains were removed, frozen, and cryosectioned for the histological detection of injector tracks in the NAc shell and core.

Data analysis. The data are expressed as the mean number of injections per session and mean number of injections during the first hour of the session in each group of rats. METH self-administration was compared across daily sessions over the initial 10 escalation sessions using a twoway repeated-measures ANOVA, followed by Bonferroni's-corrected pairwise comparison tests (access $\times$ daily session; Prism 4.0; GraphPad Software). Responding for METH under a PR schedule is expressed as the number of injections per session and was compared between LgA and ShA rats using a two-way repeated-measures ANOVA (access $\times$ session). When significant interaction and main effects of access and session were found, Student's $t$ test was performed on the number of injections per session between LgA and ShA groups under the PR schedule. The effect of nor-BNI on METH self-administration was compared using a two-way repeated-measures ANOVA, followed by Bonferroni's-corrected pairwise comparison tests (access $\times$ treatment; Prism 4.0; GraphPad Software). Immunohistochemical data were analyzed with a one-way ANOVA, followed by pairwise comparisons. For NAc shell prodynorphin level data, we also performed a Spearman's rank correlation on the ordinal data between prodynorphin and METH intake (last three sessions).

\section{Results}

Experiment 1: systemic administration of the KOR antagonist nor-BNI attenuates the escalation of METH intake associated with extended-access self-administration

Figure 1 shows a schematic diagram of all of the experimental procedures, beginning with those used in Experiment 1. METH self-administration significantly increased in LgA rats over 11 daily sessions during the escalation phase of the experiment. A two-way repeated-measures ANOVA revealed a significant interaction between access and daily session for METH intake in the first hour $\left(F_{(10,100)}=2.475, p<0.05\right)$ and a significant interaction between nor-BNI treatment and daily session for the total $6 \mathrm{~h}$ session $\left(F_{(10,100)}=4.409, p<0.001\right)$ for LgA animals. Pairwise comparison tests determined that vehicle-treated rats significantly escalated their intake by session 9 and maintained escalated intake until the final session for first hour intake (Fig. 2A) and escalated their intake in

\section{$30 \mathrm{mg} / \mathrm{kg}$ \\ Systemic \\ NorBNI

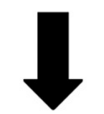

1hr Sessions 1 or 6 hr Sessions

PR1

17d Abstinence

PR2

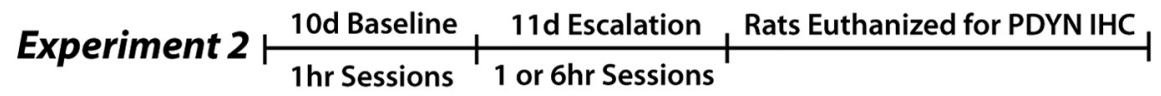

4ug/0.5ul/side

Intracranial

NorBNI

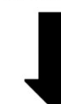

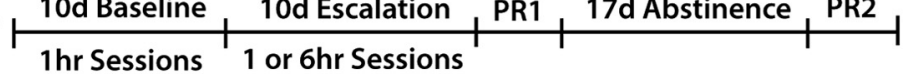

Schematic representation of experimental procedures used in Experiments 1-3.

sessions 5 and 6 and maintained escalated intake from session 8 until the final session for the entire $6 \mathrm{~h}$ session (Fig. 2B). LgA animals pretreated with nor-BNI showed an attenuation of METH intake and significant blockade of the escalation of METH intake during the first hour of self-administration (Fig. 2A), as well as over the course of the entire $6 \mathrm{~h}$ session (Fig. 2B). A two-way repeated-measures ANOVA revealed a significant main effect of nor-BNI treatment on METH intake in the first hour $\left(F_{(1,90)}=12.24, p<0.001\right)$ and total $6 \mathrm{~h}$ session $\left(F_{(1,90)}=9.857\right.$, $p<0.05)$ for LgA animals. Pairwise comparison tests determined that nor-BNI-treated rats failed to exhibit significant escalation of intake over 11 consecutive sessions in either the first hour or total $6 \mathrm{~h}$ of the session. METH self-administration in ShA rats was stable over 11 sessions.

Systemic pretreatment with nor-BNI also attenuated the elevated PR breakpoints associated with extended-access selfadministration (Fig. 2C,D). Rats were tested under the PR schedule immediately after escalation (PR1) and again after $17 \mathrm{~d}$ of abstinence (PR2) to evaluate their motivation to receive METH injections. For PR1, the two-way ANOVA revealed a significant main effect of access $\left(F_{(1,18)}=20.24, p<0.001\right)$ and a significant main effect of nor-BNI treatment $\left(F_{(1,18)}=30.4, p<\right.$ 0.001 ), with no significant interaction between the two variables. Pairwise comparison tests indicated that LgA rats showed increased PR breakpoints compared with both ShA vehicle- and nor-BNI-treated rats, and nor-BNI significantly decreased PR breakpoints under both ShA and LgA conditions compared with vehicle-treated rats (Fig. 2C). For PR2, the two-way ANOVA revealed a significant main effect of access $\left(F_{(1,17)}=7.898, p<\right.$ $0.05)$, a significant main effect of nor-BNI treatment $\left(F_{(1,17)}=\right.$ $20.61, p<0.001)$, and a significant interaction between the two variables $\left(F_{(1,17)}=6.361, p<0.05\right)$. Pairwise comparison tests indicated that LgA rats showed increased PR breakpoints compared with ShA vehicle-pretreated rats, and nor-BNI significantly decreased PR breakpoints selectively in the LgA condition compared with vehicle-treated rats (Fig. 2D). 
A

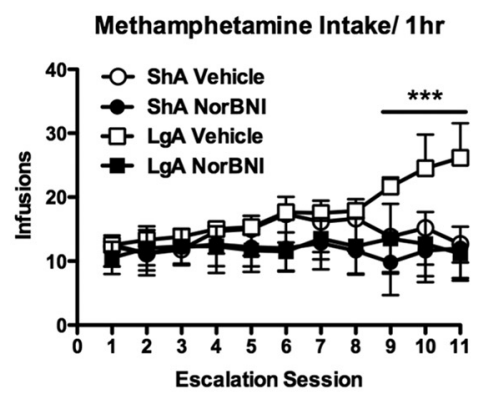

C

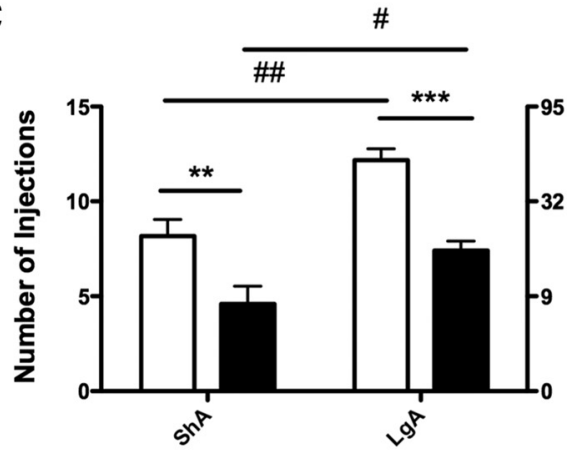

PR1
B

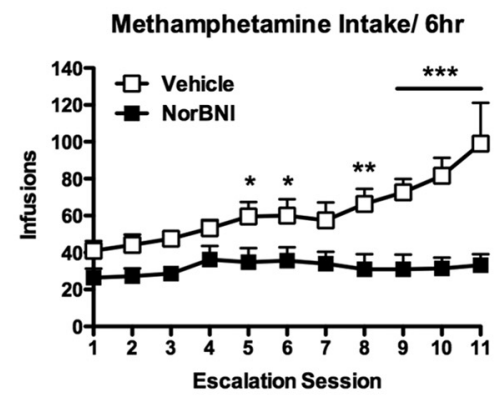

D

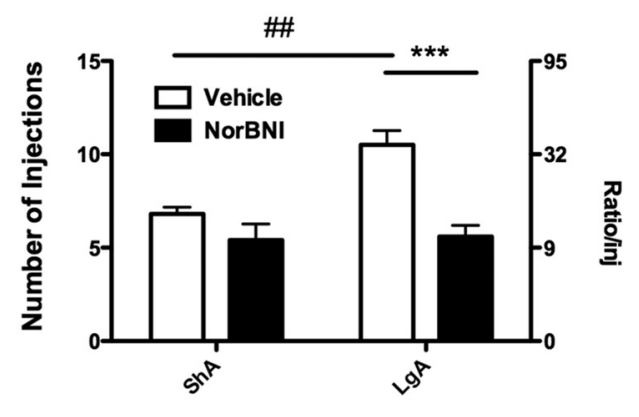

PR2

Figure 2. A, Rats that received pretreatment with nor-BNI showed an attenuation of METH intake and a significant blockade of escalation of METH intake during the first hour of selfadministration during the escalation phase of the experiment. Pairwise comparison tests determined that vehicle-pretreated rats significantly escalated their intake by session 9 and maintained escalated intake until the final session (session 1 compared with session 9,10 , or $11,{ }^{* * *} p<0.001$ ). nor-BNI-treated rats failed to demonstrate significant escalation of intake over 11 consecutive sessions. $\boldsymbol{B}$, Pretreatment with nor-BNI decreased initial METH intake and significantly blocked the escalation of METH intake during LgA sessions. Pairwise comparison tests indicated that vehicle-treated rats escalated intake by session 5 (session 1 compared with session $5,{ }^{*} p<0.05$ ) and continued to escalate their intake until the final session (session 1 compared with session 9 , 10 , or $11,{ }^{* * *} p<0.001$ ), but nor-BNI-treated rats failed to demonstrate escalation of intake over 11 consecutive sessions. Systemic administration of the KOR antagonist nor-BNI attenuated the elevated PR breakpoints associated with extended-access self-administration. nor-BNI-treated $(30 \mathrm{mg} / \mathrm{kg})$ rats were tested under a PR schedule after escalation $(\boldsymbol{C})$ and after abstinence $(\boldsymbol{D})$ to evaluate their motivation to work for METH injections. C, During PR1, rats with a history of extended access showed increased PR breakpoints, whereas nor-BNI decreased PR breakpoints. Pairwise comparison tests indicated that both nor-BNI-treated and vehicle-treated rats with a history of LgA exhibited increased PR breakpoints compared with ShA rats $\left({ }^{\#} p<0.05\right.$, $\left.{ }^{\# \#} p<0.01\right)$, and nor-BNI decreased the motivation for METH in both ShA and LgA conditions $\left({ }^{* *} p<0.01,{ }^{* * *} p<0.001\right) . \boldsymbol{D}$, In PR2, nor-BNI decreased the motivation for METH only in the LgA condition, demonstrating a selective effect in rats with an escalated PR breakpoint. Pairwise comparison tests indicated that only vehicle-treated rats with a history of LgA demonstrated increased PR breakpoints compared with ShA rats ( ${ }^{\# \#} p<0.01$ ), and nor-BNI decreased the motivation for METH only in the LgA condition ( ${ }^{* * *} p<0.001, n=5-6$ per group).

Experiment 2: extended access to METH self-administration increases prodynorphin immunoreactivity in both the core and shell subdivisions of the NAc

Figure 1 shows a schematic diagram of the experimental procedures used in Experiment 2. METH self-administration significantly increased in LgA rats over 13 daily sessions during the escalation phase of the experiment. A two-way repeatedmeasures ANOVA revealed a significant interaction between access and daily session for METH intake in the first hour $\left(F_{(12,108)}=2.869, p<0.01\right)$ and in the total $6 \mathrm{~h}$ session $\left(F_{(12,108)}=\right.$ $11.51, p<0.0001)$. The post hoc tests revealed that LgA rats significantly escalated their intake by session 11 and maintained escalated intake until the final session for first hour intake (Fig. $3 A$ ) and escalated their intake in session 9 and maintained escalated intake until the final session for the entire $6 \mathrm{~h}$ session (Fig. $3 B)$. Twenty-four hours after the final session, all of the rats were euthanized, and brain tissue was prepared for the immunohistological detection of prodynorphin. Figure $3 C$ illustrates representative photomicrographs of prodynorphin immunoreactivity in the ventral striatum. Figure $3 D$ shows the designated boundaries used for the analysis of immunoreactivity in striatal subregions as determined by Paxinos and Watson (2005). Figure 3E shows a high-resolution representative image of prodynorphin immunoreactivity in the dorsal NAc shell subregion for the LgA condition. A one-way ANOVA revealed a significant main effect of access condition on normalized optical densities of prodynorphin immunoreactivity in the NAc core $\left(F_{(2,15)}=10.72, p<0.01\right)$ and shell $\left(F_{(2,15)}=6.11, p<0.05\right)$. Pairwise comparison tests indicated that rats with either an ShA or LgA history showed an elevation in prodynorphin immunoreactivity in the NAc core (Fig. $3 F$ ) but that only rats with an LgA history showed an elevation in prodynorphin immunoreactivity in the NAc shell (Fig. $3 E$ ) compared with drug-naive littermate controls. A Spearman's rank correlation between prodynorphin level and METH intake revealed a significant correlation in the NAc shell $(p<0.001, r=$ $0.75)$.

Experiment 3: intra-NAc shell, but not core, administration of the KOR antagonist nor-BNI attenuates the escalation of METH intake associated with extended-access self-administration

Figure $1 C$ shows a schematic diagram of the experimental procedures used in Experiment 3. Based on the results of Experiment 2 that demonstrated significantly elevated prodynorphin immunoreactivity in the NAc shell in LgA animals, an additional group of rats was trained as described previously and tested for local effects of intracranial nor-BNI in this area. METH self-administration significantly increased in LgA rats over 10 daily sessions during the escalation phase of the experiment. A two-way repeatedmeasures ANOVA revealed a significant interaction between ac- 
A

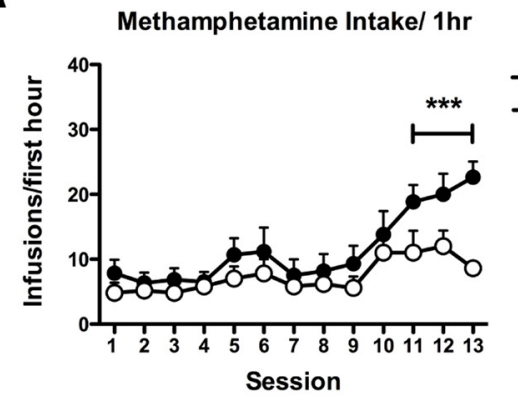

C

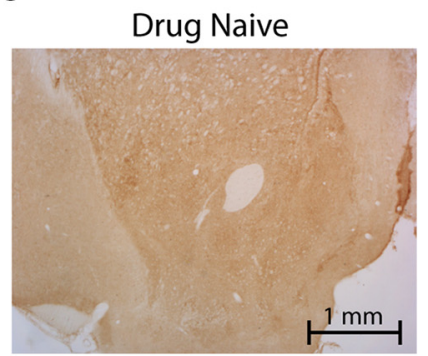

D
B

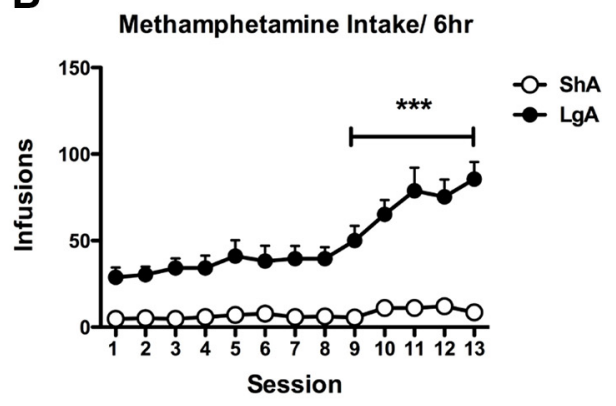

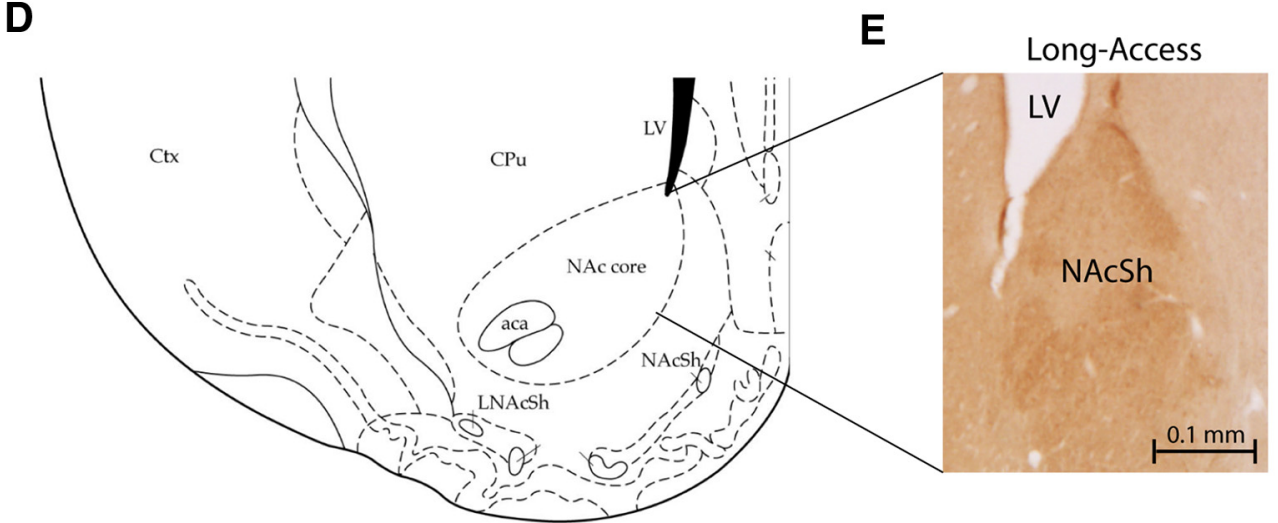

F
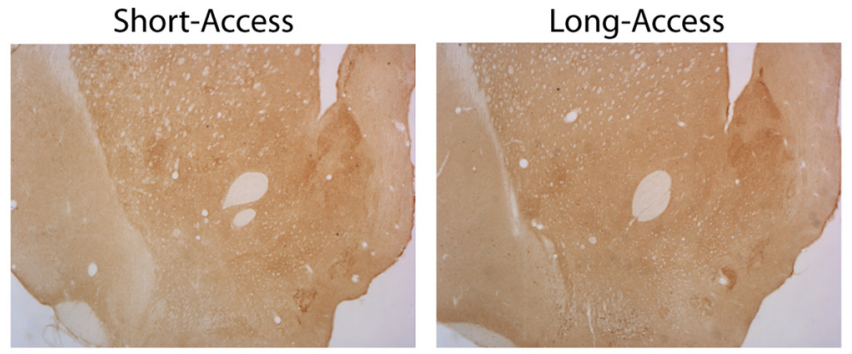

E

Long-Access
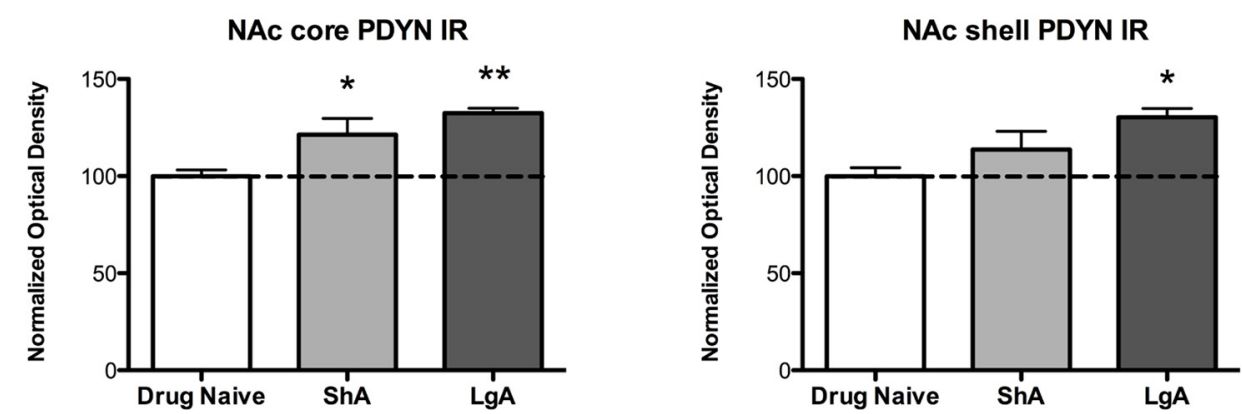

Figure 3. Extended access to METH self-administration increases prodynorphin immunoreactivity in both the core and shell subdivisions of the NAc. $A$, Rats with a history of extended access exhibited escalation of METH intake during the first hour of self-administration. Post hoc tests indicated that LgA rats escalated intake by session $11\left({ }^{* * *} p<0.0001\right)$ and continued to escalate their intake until the final session. $\boldsymbol{B}$, Rats with a history of extended access exhibited escalation of METH intake during the entire $6 \mathrm{~h}$ sessions. Post hoc tests indicated that $L g A$ rats escalated intake by session $\left.9{ }^{* * *} p<0.0001\right)$ and continued to escalate their intake until the final session. $C$, Representative photographs of prodynorphin immunoreactivity in the ventral striatum. $\boldsymbol{D}$, Representative illustration that shows the designated boundaries used for the analysis of immunoreactivity in striatal subregions as determined by Paxinos and Watson (2005). E, Photograph that shows a high-resolution representative image of prodynorphin immunoreactivity in the dorsal NAc shell subregion for the LgA condition. $\boldsymbol{F}$, Rats with a history of either ShA or LgA showed an elevation in prodynorphin immunoreactivity (IR) in the NAc core $\left({ }^{*} p<0.05,{ }^{* *} p<0.01\right)$, whereas only extended access to METH self-administration selectively increased prodynorphin immunoreactivity in the NAc shell ( ${ }^{*} p<0.05, n=6$ per group). aca, anterior part of anterior commissure; (Pu, caudate-putamen; Ctx, cortex; LNAcSh, lateral nucleus accumbens shell subregion for the LgA condition; LV, lateral ventricle; NACSh, NAc shell subregion; PDYN, prodynorphin.

cess and daily session for METH intake in the first hour $\left(F_{(9,81)}=\right.$ $3.587, p<0.001)$ and a significant interaction between nor-BNI treatment and daily session for the entire $6 \mathrm{~h}$ session $\left(F_{(9,81)}=\right.$ $2.156, p<0.05)$ in LgA animals. Pairwise comparison tests indicated that vehicle-treated rats significantly escalated their intake by session 7 and maintained escalated intake until the final session for first hour intake (Fig. 4A) and escalated their intake in session 8 and maintained escalated intake until the final session for the entire $6 \mathrm{~h}$ session (Fig. 4B). LgA animals that were pretreated with intra-NAc shell nor-BNI $(4 \mu \mathrm{g} / 0.5 \mu \mathrm{l}$ per side $)$ 
A

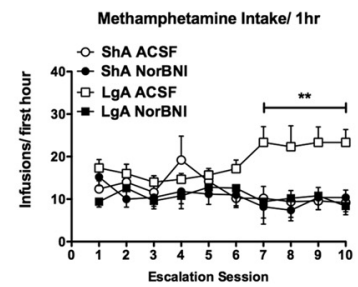

C

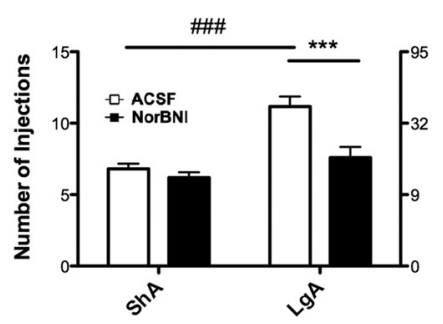

PR1
B

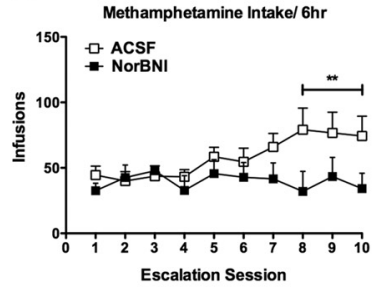

D

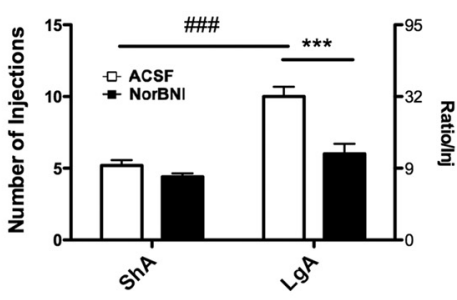

PR2

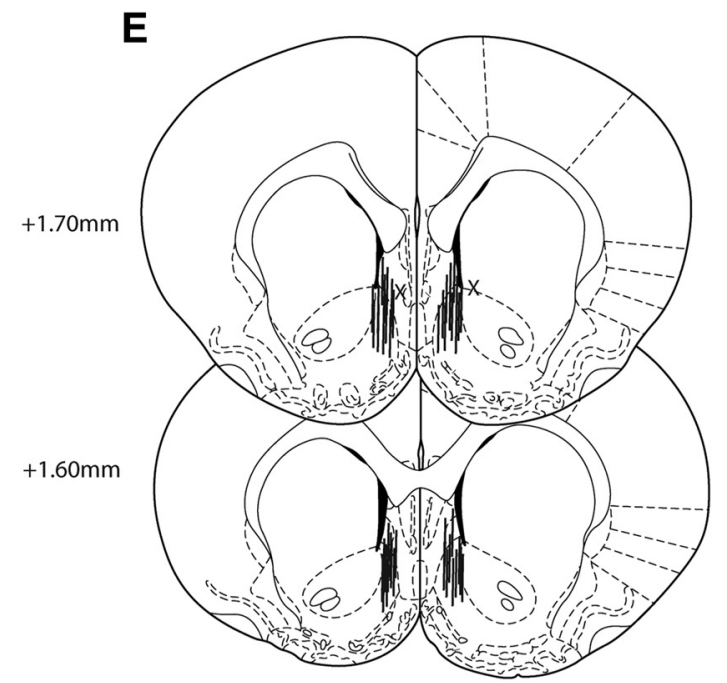

Figure 4. Intra-NAc shell administration of nor-BNI attenuated the escalation of METH intake associated with extended-access self-administration. $A$, Pretreatment with intra-NAc shell nor-BNI ( $4 \mu \mathrm{g} / 0.5 \mu \mathrm{l}$ per side) blocked the escalation of METH intake during the first hour of self-administration in LgA rats during escalation. Pairwise comparison tests indicated that aCSF-infused rats escalated intake by session $7\left({ }^{* *} p<0.001\right)$ and continued to escalate their intake until the final session $\left({ }^{* *} p<0.01\right)$, but nor-BNI-pretreated rats failed to exhibit escalation of intake over 10 consecutive sessions. $\boldsymbol{B}$, Pretreatment with intra-NAc shell nor-BNI blocked the escalation of METH intake during the $6 \mathrm{~h}$ sessions. Pairwise comparison tests indicated that aCSF-infused rats escalated intake by session 8 and continued to escalate their intake until the final session $\left({ }^{* *} p<0.01\right)$, but nor-BNI-pretreated rats failed to exhibit escalation of intake over 10 consecutive sessions. Intra-NAc shell administration of nor-BNI attenuated the elevated PR breakpoints associated with extended-access self-administration. nor-BNI-pretreated (4 $\mu \mathrm{g} / 0.5 \mu \mathrm{l}$ per side) rats were tested on a PR schedule after escalation $(\boldsymbol{C})$ and after abstinence to evaluate their motivation to work for METH injections. C, During PR1, rats with a history of extended access showed increased PR breakpoints, whereas nor-BNI decreased PR breakpoints. Pairwise comparison tests indicated that aCSF-infused rats with a history of LgA exhibited increased PR breakpoints compared with ShA rats ( ${ }^{\# \# \# ~}<$ 0.001), and nor-BNI decreased the motivation for METH selectively in the LgA condition ( $\left.{ }^{* * *} p<0.001\right)$. D, In PR2, nor-BNI decreased the motivation for METH only in the LgA condition, exhibiting a selective effect in rats with an escalated PR breakpoint. Pairwise comparison tests indicated that aCSF-infused rats with a history of LgA demonstrated increased PR breakpoints compared with ShA rats ( ${ }^{\# \#} p<0.001$ ), and nor-BNI decreased the motivation for METH only in the LgA condition ( ${ }^{* * *} p<0.001, n=5-6$ per group). E, Illustration shows cannula placements for Experiment 3 , in which black lines represent successful placements within the NAc shell subregion, and black $\times$ symbols represent missed placements outside the region of interest (range, $+1.70-1.60 \mathrm{~mm}$ relative to bregma).

showed an attenuation of METH intake and significant blockade of escalation of METH intake during the first hour of selfadministration (Fig. 4A), as well as over the course of the entire $6 \mathrm{~h}$ session (Fig. 4B). A two-way repeated-measures ANOVA revealed a significant main effect of nor-BNI treatment on METH intake in the first hour $\left(F_{(1,81)}=8.335, p<0.05\right)$ and a significant interaction between nor-BNI treatment and session $\left(F_{(9,81)}=\right.$ 9.857, $p<0.001)$ in LgA animals. Pairwise comparison tests indicated that nor-BNI-pretreated rats failed to exhibit significant escalation of intake over 10 consecutive sessions in either the first hour or total $6 \mathrm{~h}$ of the session. METH self-administration in ShA rats was stable over 10 sessions.

Intracranial pretreatment with the KOR antagonist nor-BNI also attenuated the elevated PR breakpoints associated with extended-access self-administration (Fig. 4C,D). Rats were tested under a PR schedule immediately after escalation (PR1) and immediately after $17 \mathrm{~d}$ of abstinence (PR2) to evaluate their motivation to receive $\mathrm{METH}$ injections. For PR1, the two-way ANOVA revealed a significant main effect of access $\left(F_{(1,17)}=\right.$ 23.31, $p<0.001)$, a significant main effect of nor-BNI pretreatment $\left(F_{(1,17)}=12.17, p<0.01\right)$, and a significant interaction between the two variables $\left(F_{(1,17)}=6.169, p<0.05\right)$. Pairwise comparison tests indicated that LgA rats showed increased PR breakpoints compared with ShA vehicle-treated rats, and norBNI significantly decreased PR breakpoints selectively in the LgA condition compared with vehicle-treated rats (Fig. 4C). Similarly for PR2, the two-way ANOVA revealed a significant main effect of access $\left(F_{(1,17)}=32.44, p<0.0001\right)$, a significant main effect of nor-BNI treatment $\left(F_{(1,17)}=18.25, p<0.001\right)$, and a significant interaction between the two variables $\left(F_{(1,17)}=8.109, p<0.05\right)$. Pairwise comparison tests again indicated that LgA rats showed increased PR breakpoints compared with ShA vehicle-treated rats, and nor-BNI significantly decreased PR breakpoints selectively in the $\operatorname{LgA}$ condition compared with vehicle-treated rats (Fig. $4 D$ ). Figure $4 E$ shows the cannulae placements for Experiment 3 , in which black circles represent successful placements within the NAc shell subregion, and black $\times$ symbols represent missed placements outside the region of interest.

A separate cohort of rats received intracranial injections of nor-BNI ( $4 \mu \mathrm{g} / 0.5 \mu \mathrm{l}$ per side) into the NAc core subregion exactly as described above. METH self-administration significantly increased in LgA rats over 10 daily sessions during the escalation phase of the experiment. A two-way repeated-measures ANOVA revealed a significant main effect of daily session for METH intake $\left(F_{(9,72)}=8.061, p<0.0001\right)$, but there was no significant interaction between nor-BNI treatment and daily session for the entire $6 \mathrm{~h}$ session $\left(F_{(9,72)}=1.185, p>0.05\right)$ in LgA animals (Fig. $5 A$ ). Figure $5 B$ shows the cannulae placements for core-injected animals, in which black lines represent successful placements within the NAc core subregion.

\section{Discussion}

The present study demonstrated that dynorphin-KOR interactions are critically involved in the initiation and/or expression of escalation of intake resulting from extended-access METH selfadministration. Long-lasting KOR antagonism with nor-BNI persistently decreased the motivation to take METH. These studies identified the NAc shell subregion as both an area that is 
A

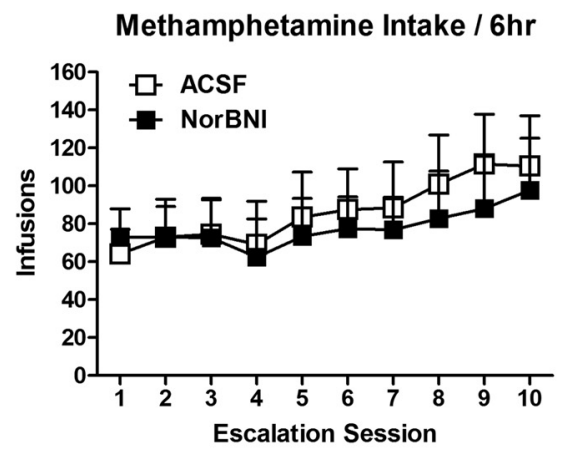

B

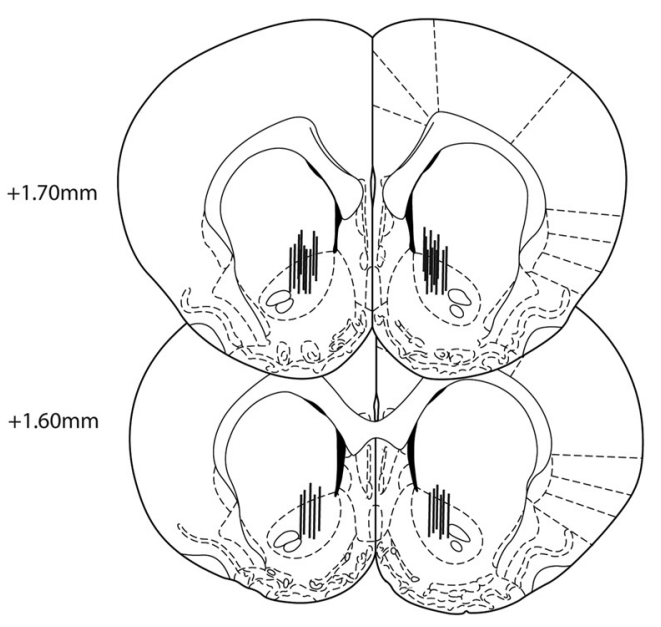

Figure 5. Intra-NAc core administration of nor-BNI did not alter the escalation of METH intake associated with extended-access self-administration. $\boldsymbol{A}$, Pretreatment with intra-NAc core nor-BNI ( $4 \mu \mathrm{g} / 0.5 \mu$ l per side) failed to alter the escalation of METH intake during $6 \mathrm{~h}$ of self-administration in LgA rats. $\boldsymbol{B}$, Illustration shows cannulae placement. Black lines represent successful placements within the NAc core subregion, and black $\times$ symbols represent missed placements outside the region of interest (range, $+1.70-1.60 \mathrm{~mm}$ relative to bregma).

influenced by extended access to METH and the local site of action for the suppressive effect of nor-BNI on METH escalation. These results indicate that the NAc shell dynorphin-KOR system is critically involved in compulsive-like METH intake.

\section{Dynorphin-KOR interactions drive drug seeking}

We report that nor-BNI administered before the beginning of LgA sessions fully blocked escalation of METH self-administration in LgA rats, without changing drug intake in ShA rats. nor-BNI also blocks the development and/or expression of escalation of intravenous heroin intake with extended access, and these effects are localized to the NAc shell (Schlosburg et al., 2013). Moreover, excessive alcohol self-administration is blocked by KOR antagonism (Walker et al., 2011), and this effect is mediated by KOR activity in the NAc shell (Nealey et al., 2011). Future studies using reversible, shorter-acting KOR antagonists will identify which of these processes (i.e., development or expression) may be affected specifically by KOR manipulation.

Repeated bouts of extended-access METH self-administration and withdrawal may create a chronic stress state that is driven by elements of an anti-reward system. Although we do not here provide direct evidence for a dysphoric-like state, Jang et al. (2013) reported elevated intracranial self-stimulation thresholds and depressive-like behaviors in METH LgA rats that paralleled the escalation in METH self-administration. Increased thresholds correlated highly with METH intake, suggesting that METH intake in LgA rats may be driven by a concomitant dysphoric-like state. Consistent with these results, Schindler et al. (2012) demonstrated that stress-induced potentiation of cocaine-induced conditioned place preference depended on local KOR signaling in the ventral striatum. Moreover, KORs are necessary for stressinduced reinstatement of heroin seeking (Zhou et al., 2013). Given that KOR agonists have been shown consistently to induce dysphoric-like states in rodents and humans, our hypothesis is that increased dynorphin-KOR activity in the ventral striatum may be driving escalation of intake via a negative reinforcement mechanism.

Activation of KOR in LgA animals during abstinence would thus be hypothesized to contribute to a "between-system" neuroadaptation (Koob and Bloom, 1988) before an extended access session that increases METH self-administration in a form of functional tolerance-taking more drug to oppose the aversive effects of KOR activation. The increased self-administration then results in homeostasis "misregulation" whereby the animal attempts to reverse a putatively low dopamine tone by selfadministering a drug that acutely releases dopamine but in turn drives upregulation of the dynorphin-KOR system and increases the deficit state (Koob et al., 2014). We have argued that this process is an allostatic mechanism leading to an altered set point for drug reward that progressively worsens (Koob and Le Moal, 2001). This hypothesis is consistent with recent work by Willuhn et al. (2014) who demonstrated that escalation of cocaine intake is driven by decreases in phasic dopamine release in the ventral striatum and that normalization of this state by the dopamine precursor L-DOPA can eliminate the escalation of cocaine intake. Thus, KOR acts as a presynaptic regulator of dopamine release, and, when the KOR system becomes sensitized by repeated psychostimulant use, it creates a state of deficient presynaptic dopamine release.

\section{KOR antagonism selectively blocks the escalation of METH self-administration}

nor-BNI attenuated escalation of drug-taking behavior in animals allowed extended access to METH but did not alter intake in rats with limited access. This result suggests that nor-BNI is not causing motor effects that disrupt operant behavior. However, one cannot totally rule out sedation as contributing to the effects in LgA rats. Nevertheless, nor-BNI had no effect on inactive lever responding in any of the experiments, further supporting that nor-BNI was not producing nonspecific effects.

Studies with limited-access self-administration models have demonstrated that KOR agonists decrease cocaine selfadministration and reinstatement (Glick et al., 1995; Schenk et al., 1999). Frequently, KOR agonists are administered directly before drug self-administration. Because KOR agonists have been shown to be strongly dysphoric, we suggest that acute activation of KOR systems can suppress behavior via punishment-like effects (possibly via decreased dopamine function) and that the KOR system modulates acute reinforcing actions by feedback suppression (Carlezon et al., 1998; Chartoff and Carlezon, 2014). Acute stimulation of KOR can antagonize the reinforcing effects of cocaine, morphine, heroin, and ethanol, whereas KOR blockade has no consistent effect (Wee and Koob, 2010). However, when drug dependence has been reached, a hyper- 
active dynorphin system decreases dopamine function sufficient to set up the learning of compulsive-like responding (via negative reinforcement). At this point, the inhibition of KOR is effective in selectively attenuating escalated drug intake (Wee et al., 2009).

We further hypothesize that the escalation of METH intake could be a response to a chronically active dynorphin system in the ventral striatum, in which excessive drug taking becomes a consequence of a KOR-dependent anti-reward state. nor-BNI persistently blocks dynorphin-KOR interactions during withdrawal, keeping METH-seeking and -taking behaviors at persistently stable levels. An alternative explanation is that nor-BNI prolongs the reward-facilitating effects of METH and thus less METH is self-administered. However, because the nor-BNI effect was selective to LgA animals, it is unlikely that nor-BNI is potentiating the rewarding effects of METH. nor-BNI also decreased $\mathrm{PR}$ responding, in which the higher breakpoint is hypothesized to reflect higher reward efficacy. Therefore, if nor-BNI was promoting the effects of METH, the breakpoints should increase in all groups.

\section{The effects of a single nor-BNI infusion were long lasting} In the current model, nor-BNI had behavioral effects that lasted $>4$ weeks. This finding is consistent with other work that has shown persistent behavioral effects using this and other similar KOR antagonists (Bruchas et al., 2006; Potter et al., 2011). Given the unique long-lasting properties of nor-BNI, we were able to persistently block the escalation of METH intake with a single pretreatment. Similarly, Chartoff et al. (2012) used nor-BNI pretreatment to block the ability of cocaine to increase reward thresholds in an intracranial self-stimulation model. Consistent with our hypothesis, nor-BNI was able to prevent the emergence of an anti-reward state after repeated treatments with cocaine. The choice of nor-BNI pretreatment in our model was made to assess the role of dynorphin-KOR interactions in the emergence of the escalation of intake. We identified a role for KOR activation in the transition from limited-access stable patterns to escalated patterns of drug taking and drug seeking.

\section{Prodynorphin immunoreactivity was upregulated in the NAc shell in LgA rats}

Psychostimulant-mediated dopamine receptor activation in the NAc shell stimulates a cascade of events that leads to CREB phosphorylation and alterations in gene expression, notably the expression of prodynorphin. Cocaine self-administration and acute METH injection have been shown to increase prodynorphin mRNA in the striatum (Hurd et al., 1992; Daunais et al., 1993; Smith and McGinty, 1994; Adams et al., 2003). Activation of dynorphin systems has been shown to feedback to decrease dopamine release and contribute to the dysphoric syndrome associated with cocaine dependence (Gray et al., 1999; Pliakas et al., 2001; Mague et al., 2003; Nestler, 2004; Todtenkopf et al., 2004; Knoll and Carlezon, 2010). The current work demonstrated that extended access to METH self-administration has similar activating effects on prodynorphin expression in the NAc shell. We cannot completely rule out the possibility that surgery and other procedural variables contributed to changes in dynorphin levels. Nevertheless, a positive correlation linking METH intake to dynorphin expression suggests an association between escalated METH intake and dynorphin-KOR signaling.

\section{nor-BNI injection directly into the NAc shell, but not the core, reproduced the behavioral effects of systemic pretreatment}

To test the functional role of KOR signaling in the NAc in LgA animals, we directly injected nor-BNI into the NAc shell and core (control region) and tested for escalation of METH selfadministration. The finding that intra-NAc shell but not core infusion of nor-BNI prevented the emergence and/or expression of the escalation of METH intake demonstrates that dynorphinKOR interactions in the NAc shell are critically involved in METH-associated escalation. Presently, very little evidence exists to pinpoint the neurocircuits directly responsible for driving compulsive-like taking and seeking behaviors, particularly for METH. METH engages overlapping neurocircuits similarly to other psychostimulants, such as cocaine and amphetamine. METH seeking during cue- and METH-primed reinstatement can be blocked by selective inactivation of the prelimbic cortex and NAc (Roca and Kalivas, 2010). However, few studies have addressed how the neuroplasticity underlying escalation in an extended-access model may be distinct from other psychostimulants and limited-access models, leaving an essentially unexplored area of research.

The current work contributes to these questions by establishing dynorphin-KOR signaling in the NAc shell as an essential contributor to the emergence of these behaviors. The NAc core and shell have been implicated in different aspects of drug selfadministration. The NAc shell has been hypothesized to mediate the rewarding effects of drugs and the associative learning that contributes to the enhancement of the reinforcing effects of psychostimulants, whereas the NAc core is involved in the motor expression of motivated behavior, goal-directed behavior, and incentive habits (Di Chiara et al., 1999; Ito et al., 2004; Larson et al., 2011). The present results indicate that the KOR system in the NAc shell, but not the NAc core, is required for escalation of METH self-administration.

In summary, the current study identified an essential role for NAc shell dynorphin-KOR signaling in the emergence and/or expression of compulsive-like METH seeking and taking. Prodynorphin was upregulated selectively in the NAc shell in which local nor-BNI infusion had its behavioral effects, suggesting that dynorphin-KOR systems in the NAc shell become sensitized during extended-access METH self-administration to help drive increased drug seeking via negative reinforcement processes.

\section{References}

Adams DH, Hanson GR, Keefe KA (2003) Distinct effects of methamphetamine and cocaine on preprodynorphin messenger RNA in rat striatal patch and matrix. J Neurochem 84:87-93. CrossRef Medline

Ahmed SH, Koob GF (1998) Transition from moderate to excessive drug intake: change in hedonic set point. Science 282:298-300. CrossRef Medline

American Psychiatric Association (2000) Diagnostic and statistical manual of mental disorders, IV-TR. Washington, DC: American Psychiatric Press.

Bruchas MR, Chavkin C (2010) Kinase cascades and ligand-directed signaling at the kappa opioid receptor. Psychopharmacology (Berl) 210:137147. CrossRef Medline

Bruchas MR, Macey TA, Lowe JD, Chavkin C (2006) Kappa opioid receptor activation of p38 MAPK is GRK3- and arrestin-dependent in neurons and astrocytes. J Biol Chem 281:18081-18089. CrossRef Medline

Carlezon WA Jr, Thome J, Olson VG, Lane-Ladd SB, Brodkin ES, Hiroi N, Duman RS, Neve RL, Nestler EJ (1998) Regulation of cocaine reward by CREB. Science 282:2272-2275. CrossRef Medline

Chartoff EH, Carlezon WA Jr (2014) Drug withdrawal conceptualized as a stressor. Behav Pharmacol 25:473-492. CrossRef Medline

Chartoff E, Sawyer A, Rachlin A, Potter D, Pliakas A, Carlezon WA (2012) 
Blockade of kappa opioid receptors attenuates the development of depressive-like behaviors induced by cocaine withdrawal in rats. Neuropharmacology 62:167-176. CrossRef Medline

Chavkin C, James IF, Goldstein A (1982) Dynorphin is a specific endogenous ligand of the kappa opioid receptor. Science 215:413-415. CrossRef Medline

Cole RL, Konradi C, Douglass J, Hyman SE (1995) Neuronal adaptation to amphetamine and dopamine: molecular mechanisms of prodynorphin gene regulation in rat striatum. Neuron 14:813-823. CrossRef Medline

Daunais JB, Roberts DC, McGinty JF (1993) Cocaine self-administration increases preprodynorphin, but not c-fos, mRNA in rat striatum. Neuroreport 4:543-546. CrossRef Medline

Di Chiara G, Tanda G, Bassareo V, Pontieri F, Acquas E, Fenu S, Cadoni C, Carboni E (1999) Drug addiction as a disorder of associative learning. Role of nucleus accumbens shell/extended amygdala dopamine. Ann N Y Acad Sci 877:461-485. CrossRef Medline

Glick SD, Maisonneuve IM, Raucci J, Archer S (1995) Kappa opioid inhibition of morphine and cocaine self-administration in rats. Brain Res 681: 147-152. CrossRef Medline

Gray AM, Rawls SM, Shippenberg TS, McGinty JF (1999) The kappa-opioid agonist, U-69593, decreases acute amphetamine-evoked behaviors and calcium-dependent dialysate levels of dopamine and glutamate in the ventral striatum. J Neurochem 73:1066-1074. CrossRef Medline

Hadamitzky M, Markou A, Kuczenski R (2011) Extended access to methamphetamine self-administration affects sensorimotor gating in rats. Behav Brain Res 217:386-390. CrossRef Medline

Horan P, Taylor J, Yamamura HI, Porreca F (1992) Extremely long-lasting antagonistic actions of nor-binaltorphimine (nor-BNI) in the mouse tailflick test. J Pharmacol Exp Ther 260:1237-1243. Medline

Hurd YL, Brown EE, Finlay JM, Fibiger HC, Gerfen CR (1992) Cocaine selfadministration differentially alters mRNA expression of striatal peptides. Brain Res Mol Brain Res 13:165-170.

Hyman SE, Cole RL, Konradi C, Kosofsky BE (1995) Dopamine regulation of transcription factor-target interactions in rat striatum. Chem Senses 20:257-260. CrossRef Medline

Ito R, Robbins TW, Everitt BJ (2004) Differential control over cocaineseeking behavior by nucleus accumbens core and shell. Nat Neurosci 7:389-397. CrossRef Medline

Jang CG, Whitfield T, Schulteis G, Koob GF, Wee S (2013) A dysphoric-like state during early withdrawal from extended access to methamphetamine self-administration in rats. Psychopharmacology (Berl) 225:753-763. CrossRef Medline

Jones DN, Holtzman SG (1992) Long term kappa-opoid receptor blockade following nor-binaltorphimine. Eur J Pharmacol 215:345-348. Medline

Kitamura O, Wee S, Specio SE, Koob GF, Pulvirenti L (2006) Escalation of methamphetamine self-administration in rats: a dose-effect function. Psychopharmacology (Berl) 186:48-53. CrossRef Medline

Knoll AT, Calezon WA Jr (2010) Dynorphin, stress, and depression. Brain Res 1314:56-73. CrossRef Medline

Knoll JH, Lichter P, Bakdounes K, Eltoum IE (2007) In situ hybridization and detection using nonisotopic probes. Curr Protoc Mol Biol 14:14.7. CrossRef Medline

Koob GF, Bloom FE (1988) Cellular and molecular mechanisms of drug dependence. Science 242:715-723. CrossRef Medline

Koob GF, Le Moal M (2001) Drug addiction, dysregulation of reward, and allostasis. Neuropsychopharmacology 24:97-129. CrossRef Medline

Koob GF, Buck CL, Cohen A, Edwards S, Park PE, Schlosburg JE, Schmeichel B, Vendruscolo LF, Wade CL, Whitfield TW Jr, George O (2014) Addiction as a stress surfeit disorder. Neuropharmacology 76:370-382. CrossRef Medline

Larson EB, Graham DL, Arzaga RR, Buzin N, Webb J, Green TA, Bass CE, Neve RL, Terwilliger EF, Nestler EJ, Self DW (2011) Overexpression of CREB in the nucleus accumbens shell increases cocaine reinforcement in self-administering rats. J Neurosci 31:16447-16457. CrossRef Medline

Mague SD, Pliakas AM, Todtenkopf MS, Tomasiewicz HC, Zhang Y, Stevens WC Jr, Jones RM, Portoghese PS, Carlezon WA Jr (2003) Antidepressantlike effects of kappa-opioid receptor antagonists in the forced swim test in rats. J Pharmacol Exp Ther 305:323-330. CrossRef Medline

Mandyam CD, Wee S, Crawford EF, Eisch AJ, Richardson HN, Koob GF (2008) Varied access to intravenous methamphetamine self-administration differentially alters adult hippocampal neurogenesis. Biol Psychiatry 64:958-965. CrossRef Medline
Meshul CK, McGinty JF (2000) Kappa opioid receptor immunoreactivity in nucleus accumbens shell and caudate-putamen is primarily associated with synaptic vesicles in axons. Neuroscience 96:91-99. CrossRef Medline

Mucha RF, Herz A (1985) Motivational properties of kappa and mu opioid receptor agonists studied with place and taste preference conditioning. Psychopharmacology (Berl) 86:274-280. Medline

Nealey KA, Smith AW, Davis SM, Smith DG, Walker BM (2011) Kappaopioid receptors are implicated in the increased potency of intraaccumbens nalmefene in ethanol-dependent rats. Neuropharmacology 61:35-42. CrossRef Medline

Nestler EJ (2004) Molecular mechanisms of drug addiction. Neuropharmacology 47:24-32. CrossRef Medline

Orio L, Wee S, Newman AH, Pulvirenti L, Koob GF (2010) The dopamine D3 receptor partial agonist CJB090 and antagonist PG 01037 decrease progressive ratio responding for methamphetamine in rats with extended-access. Addict Biol 15:312-323. CrossRef Medline

Parsegian A, Glen WB Jr, Lavin A, See RE (2011) Methamphetamine selfadministration produces attentional set-shifting deficits and alters prefrontal cortical neurophysiology in rats. Biol Psychiatry 69:253-259. CrossRef Medline

Paxinos G, Watson C (2006) The rat brain in sterotaxic coordinates. San Diego: Academic.

Pfeiffer A, Brantl V, Herz A, Emrich HM (1986) Psychotomimesis mediated by kappa opiate receptors. Science 233:774-776. CrossRef Medline

Pliakas AM, Carlson RR, Neve RL, Konradi C, Nestler EJ, Carlezon WA Jr (2001) Altered responsiveness to cocaine and increased immobility in the forced swim test associated with elevated cAMP response elementbinding protein expression in nucleus accumbens. J Neurosci 21:73977403. Medline

Potter DN, Damez-Werno D, Carlezon WA Jr, Cohen BM, Chartoff EH (2011) Repeated exposure to the $\kappa$-opioid receptor agonist salvinorin A modulates extracellular signal-regulated kinase and reward sensitivity. Biol Psychiatry 70:744-753. CrossRef Medline

Reichel CM, Schwendt M, McGinty JF, Olive MF, See RE (2011) Loss of object recognition memory produced by extended access to methamphetamine self-administration is reversed by positive allosteric modulation of metabotropic glutamate receptor 5. Neuropsychopharmacology 36:782792. CrossRef Medline

Richardson NR, Roberts DCS (1996) Progressive ratio schedules in drug self-administration studies in rats: a method to evaluate reinforcing efficiacy. J Neurosci Methods 66:1-11. CrossRef Medline

Roberts DC, Koob Gf, Klonoff P, Fibiger HC (1980) Extinction and recovery of cocaine self-administration following 6-hydroxydopamine lesions of the nucleus accumbens. Pharmacol Biochem Behav 12:781-787. CrossRef Medline

Rocha A, Kalivas PW (2010) Role of the prefrontal cortex and nucleus accumbens in reinstating methamphetamine seeking. Eur J Neurosci 31: 903-909. CrossRef Medline

Rogers JL, De Santis S, See RE (2008) Extended methamphetamine selfadministration enhances reinstatement of drug seeking and impairs novel object recognition in rats. Psychopharmacology (Berl) 199:615-624. CrossRef Medline

Schenk S, Partridge B, Shippenberg TS (1999) U69593, a kappa-opioid agonist, decreases cocaine self-administration and decreases cocaineproduced drug-seeking. Psychopharmacology (Berl) 144:339-346. CrossRef

Schindler Ag, Messinger DI, Smith JS, Shankar H, Gustin RM, Schattauer SS, Lemos JC, Chavkin NW, Hagan CE, Neumaier JF, Chavkin C (2012) Stress produces aversion and potentiates cocaine reward by releasing endogenous dynorphins in the ventral striatum to locally stimulate serotonin reuptake. J Neurosci 32:17582-17596. CrossRef Medline

Schlosburg JE, Whitfield TW Jr, Park PE, Crawford EF, George O, Vendruscolo LF, Koob GF (2013) Long-term antagonism of $\kappa$ opioid receptors prevents escalation of and increased motivation for heroin intake. J Neurosci 33:19384-19392. CrossRef Medline

Schwendt M, Rocha A, See RE, Pacchioni AM, McGinty JF, Kalivas PW (2009) Extended methamphetamine self-administration in rats results in a selective reduction of dopamine transporter levels in the prefrontal cortex and dorsal striatum not accompanied by marked monoaminergic depletion. J Pharmacol Exp Ther 331:555.562. CrossRef Medline

Shippenberg TS, Zapata A, Chefer VI (2007) Dynorphin and the pathophys- 
iology of drug addiction. Pharmacol Ther 116:306-321. CrossRef Medline

Simpson JN, McGinty JF (1995) Forskolin induces preproenkephalin and preprodynorphin mRNA in rat striatum as demonstrated by in situ hybridization histochemistry. Synapse 19:151-159. CrossRef Medline

Smith AJ, McGinty JF (1994) Acute amphetamine or methamphetamine alters opioid peptide mRNA expression in rat striatum. Brain Res Mol Brain Res 21:359-362. Medline

Todtenkopf MS, Marcus JF, Portoghese PS, Carlezoh WA Jr (2004) Effects of $\kappa$-opioid receptor ligands on intracranial self-stimulation in rats. Psychopharmacology (Berl) 172:463-470. CrossRef Medline

Svingos AL, Colago EE, Pickel VM (1999) Cellular sites for dynorphin activation of kappa-opioid receptors in the rat nucleus accumbens shell. J Neurosci 19:1804-1813. Medline

Walker BM, Zorilla EP, Koob GF (2011) Systemic $\kappa$-opioid receptor antagonism by nor-binaltorphimine reduces dependence-induced excessive alcohol self-administration in rats. Addict Biol 16:116-119. CrossRef Medline

Watson SJ, Khachaturian H, Akil H, Coy DH, Goldstein A (1982) Compar- ison of the distribution of dynorphin systems and enkephalin systems in brain. Science 218:1134-1136. CrossRef Medline

Wee S, Koob GF (2010) The role of the dynorphin-KOR opioid system in the reinforcing effects of drugs of abuse. Psychopharmacology 210:121135. CrossRef Medline

Wee S, Wang Z, Woolverton WL, Pulvirenti L, Koob GF (2007) Effect of aripiprazole, a partial $\mathrm{D}_{2}$ receptor agonist, on increased rate of methamphetamine self-administration in rats with prolonged access. Neuropsychopharmacology 32:2238-2247. CrossRef Medline

Wee S, Orio L, Ghirmai S, Cashman JR, Koob GF (2009) Inhibition of kappa opioid receptors attenuated increased cocaine intake in rats with extended access to cocaine. Psychopharmacology 205:565-575. CrossRef Medline

Willuhn I, Burgeno LM, Groblewski PA, Phillips PE (2014) Excessive cocaine use results from decreased phasic dopamine signaling in the striatum. Nat Neurosci 17:704-709. Medline

Zhou Y, Leri F, Grella SL, Aldrich JV, Kreek MJ (2013) Involvement of dynorphin and kappa opioid receptor in yohimbine-induced reinstatement of heroin seeking in rats. Synapse 67:358-361. CrossRef Medline 